\title{
In situ measurements of righting behavior in the common sea urchin Lytechinus variegatus: the importance of body size, substrate type, and covering material
}

\author{
R. C. Challener ${ }^{1, *}$, J. B. McClintock ${ }^{2}$ \\ ${ }^{1}$ Bellarmine University, Department of Biology, Louisville, KY 40205, USA \\ ${ }^{2}$ University of Alabama at Birmingham, Department of Biology, Birmingham, AL 35294, USA
}

\begin{abstract}
Righting behavior has been used extensively in laboratory studies of sea urchins as an indicator of stress under various environmental conditions. In situ measurements of the natural righting response of sea urchins would serve to place such laboratory measurements in an ecological context as well as potentially validate laboratory control conditions. We investigated the righting response of the sea urchin Lytechinus variegatus in seagrass and sand bottom habitats of Saint Joseph's Bay, Florida. Field-measured righting times (other than the exception mentioned below) in L. variegatus were similar to those measured in laboratory studies. Moreover, as seen in multiple sea urchin species in laboratory studies, smaller individuals exhibited significantly shorter righting times than larger individuals. Importantly, sea urchins lacking covering material (shell material, seagrass blades) that were placed on open sand patches took significantly longer to right than those with covering material placed on sand patches. Our field observations indicate the importance of sea urchin size, substrate type, and the presence or absence of covering materials when making righting measurements in the laboratory or the field. Our findings also suggest that higher water velocities facilitate righting, as at higher flows on sand patches, the presence/absence of covering material no longer significantly impacted righting time. These findings are ecologically important as they indicate that, under certain natural conditions (sand substrate, low availability of covering materials and low water velocities), L. variegatus that are displaced onto their aboral side are more vulnerable to predation.
\end{abstract}

KEY WORDS: Righting response $\cdot$ Covering behavior $\cdot$ Soft bottom $\cdot$ Echinodermata $\cdot$ Echinoidea

\section{INTRODUCTION}

Echinoderms are widely known for their ability to right themselves from an aboral position (Hyman 1955, Reese 1966). This righting behavior usually involves the coordinated movements of tube feet and spines (Lawrence 1976a) and is thought to be a simple neurological reflex (Reese 1966, Binyon 1972). Historically, the righting response has been exploited in laboratory studies, particularly with asteroids and echinoids, as a measure of stress under environmen-

${ }^{*}$ Corresponding author: rchallener@bellarmine.edu tal change (e.g. Kleitman 1941, Giese \& Farmanfarmaian 1963, Percy 1973, Lawrence 1975, Lares \& McClintock 1991, Böttger et al. 2001, Challener \& McClintock 2013) or as a diagnosis of sea urchin disease (e.g. Scheibling \& Stephenson 1984). In instances where righting responses are employed, sea urchins or sea stars are collected and transported to the laboratory, where they are placed in aquaria or seawater tables. Several days to weeks are usually allowed for adjustment to laboratory conditions prior to measuring righting responses, as a technique to

() The authors 2017. Open Access under Creative Commons by Attribution Licence. Use, distribution and reproduction are unrestricted. Authors and original publication must be credited. 
evaluate exposure to a given stressor. Although adjustment to laboratory settings is necessary to ensure that animal well-being is optimal and to minimize variation between individuals (Schapiro \& Everitt 2006), laboratory conditions often do not reflect the natural environment and therefore have the potential to produce experimental results that vary from those observed in the field. Assessing righting responses under natural conditions would permit comparisons with laboratory-based righting times. Thus, such knowledge has the potential to validate laboratory studies, as well as provide valuable information on ecologically relevant righting times. Yet, to our knowledge, righting behavior has never been measured for any echinoid or asteroid under natural conditions in the field.

The common regular sea urchin Lytechinus variegatus is distributed throughout the Caribbean and Gulf of Mexico, occurs primarily in shallow seagrass habitats (see Watts et al. 2013 for review) and displays righting behavior: when placed on its aboral side with its mouth facing upward, the sea urchin will reorient itself by rotating $180^{\circ}$ until its oral surface is again on the substrate (Kleitman 1941). Smaller urchins are likely to right more rapidly than larger urchins as smaller body size in regular sea urchins has been associated with reduced righting time in laboratory studies (Percy 1973, Sonnenholzner et al. 2010). Populations of $L$. variegatus are known to display polymodal size distributions with discrete year classes present throughout the year (e.g. Beddingfield \& McClintock 2000) and therefore righting responses may be expected to vary with size in the field.

Other factors that may influence the righting response in $L$. variegatus include substrate type and presence/absence of covering material. In Saint Joseph's Bay, Florida, densities of $L$. variegatus are relatively higher in seagrass (Thalassia testudinum) patches in comparison to sand patches, yet individuals have been observed on sand patches (e.g. 8 individuals $\mathrm{m}^{-2}$ ), especially in winter months when less seagrass is present (Beddingfield \& McClintock 2000). L. variegatus has greater clinging power (adherence to an experimental substrate) on a smooth surface versus a rough surface (Sharp \& Gray 1962). Whether seagrass blades may function as smooth surfaces and sand particles as a rough surface is not known, nor is the righting response of $L$. variegatus in either seagrass beds or sand patches. Finally, $L$. variegatus is well known for its covering behavior, holding materials such as small shells, pebbles, and seagrass blades on its aboral surface (Field 1892, Amato et al. 2008). As both the spines and tube feet facilitate the righting response in sea urchins (Lawrence 1976b), it is possible that the presence of covering material interferes with the ability to right, yet to date it is unknown whether this is the case.

The purpose of the present study was to conduct the first analysis of righting behavior in a common sea urchin in its natural benthic environment. For both small and large individuals, we measured the time required to right on the same substrate (seagrass), each with and without covering material, to evaluate the potential effect of size and presence/ absence of covering material on in situ righting times. We then took large individuals (to eliminate size as a factor), with and without covering material, and measured the time require to right on 2 natural substrates (sand and seagrass), to evaluate the potential effect of substrate type and presence/absence of covering material on in situ righting times.

\section{MATERIALS AND METHODS}

Field observations were carried out in May 2014 and 2015 during daylight hours in Eagle Harbor, a small bay located within Saint Joseph's Bay State Park, Florida $\left(29^{\circ} 46^{\prime} \mathrm{N}, 85^{\circ} 22^{\prime} \mathrm{W}\right)$ where densities of Lytechinus variegatus as high as $35 \mathrm{~m}^{-2}$ have been recorded (Beddingfield \& McClintock 2000). All experiments were carried out during daylight in shallow ( $<2 \mathrm{~m}$ depth) water where researchers were able to stand and/or kneel while handling and observing sea urchins. Individual sea urchins were handcollected and righting measurements were made within the same seagrass beds from which urchins were collected or immediately adjacent to seagrass beds where urchins were collected for sand-patch treatments. Urchins were maintained under water at all times in order to minimize air exposure, with the exception of a period of less than $30 \mathrm{~s}$ such that digital images could be taken (see below). In treatments where covering material was removed, this was carefully cleaned from the test under water by hand in an effort to minimize any tube foot damage. Righting behavior measurements were made by gently placing sea urchins onto their aboral side and recording the length of time required for an individual to lift its oral surface to attain a $90^{\circ}$ angle with the substrate (Percy 1973). Size measurements (diameter) of each individual were made by taking a digital image of each urchin adjacent a ruler and then later using Image J software (Schneider et al. 2012).

In studies conducted in 2014, ambient seawater temperature was measured using a YSI 85 meter 
(YSI) and salinity was measured using a Vital Sine ${ }^{\mathrm{TM}}$ SR6 salinity refractometer. In 2015, ambient seawater temperature, dissolved oxygen, and salinity were measured using a YSI Professional Plus multiparameter water quality meter (YSI). Measurements were made at the beginning and end of each set of righting observations.

\section{Effects of body size and presence of covering materials on righting}

In 2014, we employed a $2 \times 2$ factorial design to assess whether body size (test diameter) and the presence/absence of covering material impacted righting times in small and large $L$. variegatus in seagrass beds. A total of 53 small sea urchins (diameter $1.67 \pm$ $0.04 \mathrm{~cm}$, mean $\pm 1 \mathrm{SE}$ ) carrying covering material were hand-collected haphazardly from a seagrass bed. For 26 of the individuals, covering material was left in place, while it was completely removed from the remaining 27 individuals. A similar regime was carried out for 60 large sea urchins (diameter $4.07 \pm$ $0.05 \mathrm{~cm}$ ), with 30 sea urchins left with their covering material attached and 30 individuals with it removed. Each measurement involved turning an individual gently by hand on to its aboral side in a seagrass bed and measuring the time to right (see above).

\section{Effects of presence of covering materials and substrate type on righting}

In a second $2 \times 2$ factorial design, we tested whether the presence/absence of covering material and substrate type (seagrass or sand patch) influenced the time required to right in large $L$. variegatus. The 60 large sea urchins collected above were used in this experiment. Covering material was left in place on 30 individuals and completely removed from the remaining 30 individuals prior to measuring righting times within a seagrass bed. The same methodology was employed with 40 additional large individuals with righting times measured for 20 with covering material and 20 without covering material, but righting times were measured on an open sand patch rather than within a seagrass bed.

\section{Water current measurements and righting}

In order to evaluate whether in situ currents might impact righting times in large $L$. variegatus with and without covering material and on sand or seagrass patches, we repeated the above experiment in 2015 and at the same time measured in situ currents. We again employed a $2 \times 2$ factorial design to examine 4 sea urchin treatments: (1) presence of covering material (mean test diameter $3.60 \pm 0.17 \mathrm{~cm}, \mathrm{n}=15$ ) and a substrate of seagrass, (2) absence of covering material (mean test diameter $3.49 \pm 0.21 \mathrm{~cm}, \mathrm{n}=15$ ) and a substrate of seagrass, (3) presence of covering material (mean test diameter $3.70 \pm 0.20 \mathrm{~cm}, \mathrm{n}=15$ ) and a substrate of sand, and (4) absence of covering material (mean test diameter $3.66 \pm 0.17 \mathrm{~cm}, \mathrm{n}=15$ ) and a substrate of sand. Linear water velocities were approximated using a Geopacks MFP51 stream flowmeter that was placed within $0.1 \mathrm{~m}$ of the sea urchin being observed and recorded throughout righting. Experiments were carried out in May 2015 during daylight over a $2 \mathrm{~d}$ period with a different substrate being tested each day.

\section{Statistical analysis}

Transformation of data was performed when assumptions of normality (Shapiro Wilk test) were not met. For the $20142 \times 2$ factorial experiments on the potential impacts of size and covering material, a 2way fixed effects ANOVA (following the methods of Conover \& Iman 1981) was performed where ranktransformed time-to-right was the dependent variable and size ( 2 categories) and covering material (present/ absent) were independent variables. For the $20142 \times$ 2 factorial experiments on the effects of covering material and substrate (for same-sized sea urchins), a 2way fixed effects ANOVA was performed where rank-transformed time-to-right was the dependent variable and covering material and substrate (each with 2 categories) were the independent variables. A nonparametric Spearman's correlation analysis was used in order to determine that size was not significantly correlated with righting times and did not need to be included in the $2 \times 2$ factorial experiment on covering material and substrate effects.

For the 2015 experiment carried out over 2 d, righting response times were first compared using a nonparametric 2-sample $t$-test (Mann-Whitney) in order to determine whether day affected righting times. Water velocities measured on each day were compared using a Mann-Whitney rank sum test and were found to be significantly different; therefore, we could not compare righting times collected on different days as a different substrate was tested on each day (seagrass on Day 1, sand patch on Day 2). 
To determine if the presence of covering material affected righting times on sand patches (all data that was measured on Day 2), a nonparametric Spearman's correlation analysis was used in order to determine that size and water velocity were not significantly correlated with righting times. Therefore size and water velocity did not need to be included in the statistical analysis and a 1-way fixed effects ANOVA was performed on rank transformed time-to-right with covering material (presence/absence) as the categorical independent variable.

Statistical analyses were performed using Microsoft Excel 2010, SigmaPlot 12.0, and IBM SPSS Statistics 23.

\section{RESULTS}

\section{Effects of body size and presence of covering materials on righting}

In our 2014 experiment examining the potential impact of body size and the presence or absence of covering material on righting in Lytechinus variegatus within a patch of seagrass, we detected no significant interaction effect between body size and covering on righting (Fig. 1, 2-way ANOVA, $p=0.063$, df = $1,112)$. However, while the presence or absence of covering material did not affect righting times $(\mathrm{p}=$ $0.441, \mathrm{df}=1,112)$, body size had a significant effect $(p<0.001, d f=1,112)$. Large sea urchins took significantly more time to right than did small individuals (mean \pm SE righting time for large sea urchins $94.1 \pm$ $9.7 \mathrm{~s}$; small sea urchins $39.64 \pm 3.4 \mathrm{~s}$ ). Moreover, there was considerably more variation in righting times for large than for small sea urchins (Fig. 2).

\section{Effects of presence of covering materials and substrate type on righting}

In our 2014 experiment examining the potential impact of covering material and substrate type on righting in large $L$. variegatus, we found no significant correlation between body size and righting time, indicating that the size of sea urchins in these experiments did not affect righting times (Spearman's correlation coefficient analysis, $\mathrm{p}>0.254$ for all 4 treatments). We detected a significant interaction effect between presence/absence of covering material and substrate type ( 2 -way ANOVA, $\mathrm{p}<0.001, \mathrm{df}=1,99$ ). On sand patches, sea urchins that lacked covering material required a significantly longer period of time to right than did sea urchins with covering mate-
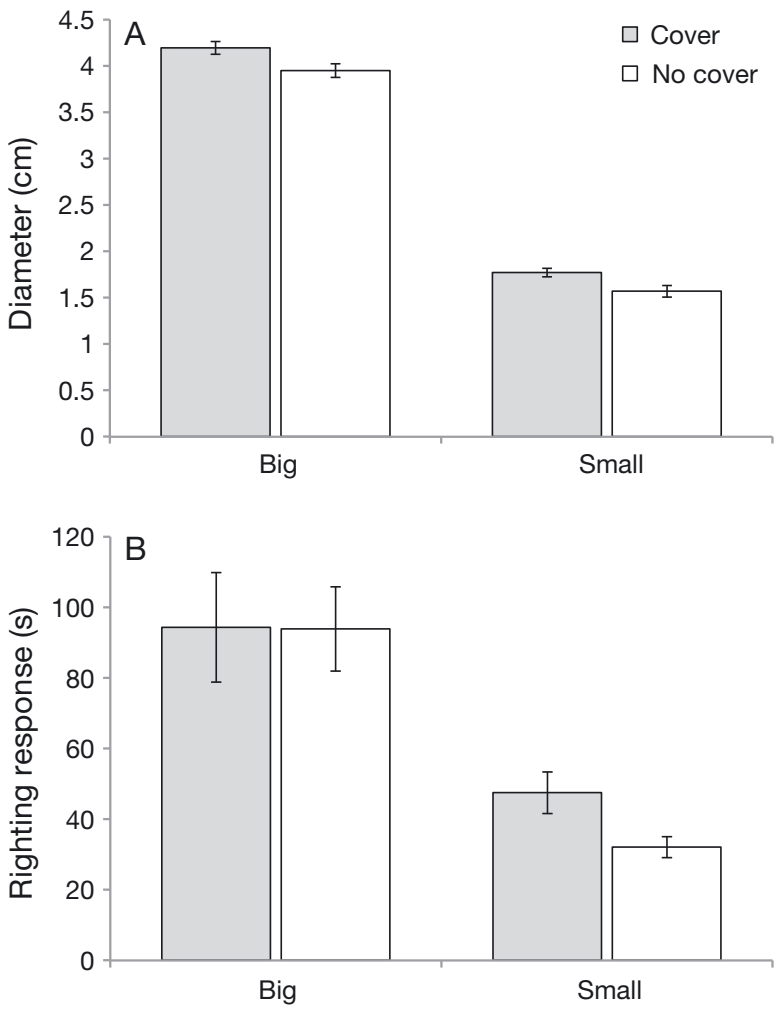

Fig. 1. Experiments in 2014 on a seagrass bed comparing sea urchin Lytechinus variegatus size and presence/absence of covering material ('cover'). Mean \pm SE (A) diameter and (B) righting time for big ( $\mathrm{n}=30$ in each treatment) and small sea urchins with $(\mathrm{n}=26)$ and without cover $(\mathrm{n}=27)$. Righting times between size classes were significantly different $(\mathrm{p}<$ 0.001 ) by 2 -way ANOVA with a Tukey post-hoc test

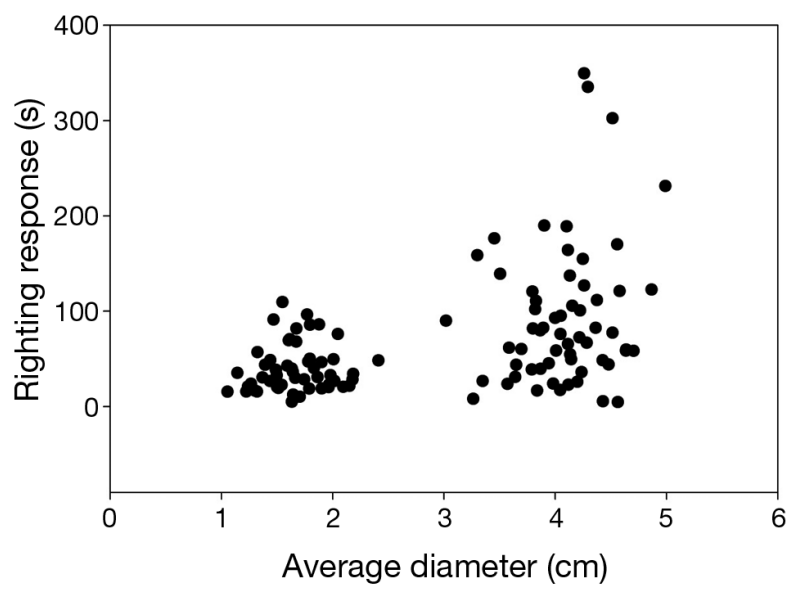

Fig. 2. Sea urchin Lytechinus variegatus size versus righting response in seagrass beds from experiments performed in 2014

rial on sand patches, or sea urchins with or without covering material in seagrass patches, despite having similar test diameters (Fig. 3A). Mean \pm SE righting times for those individuals lacking covering material 

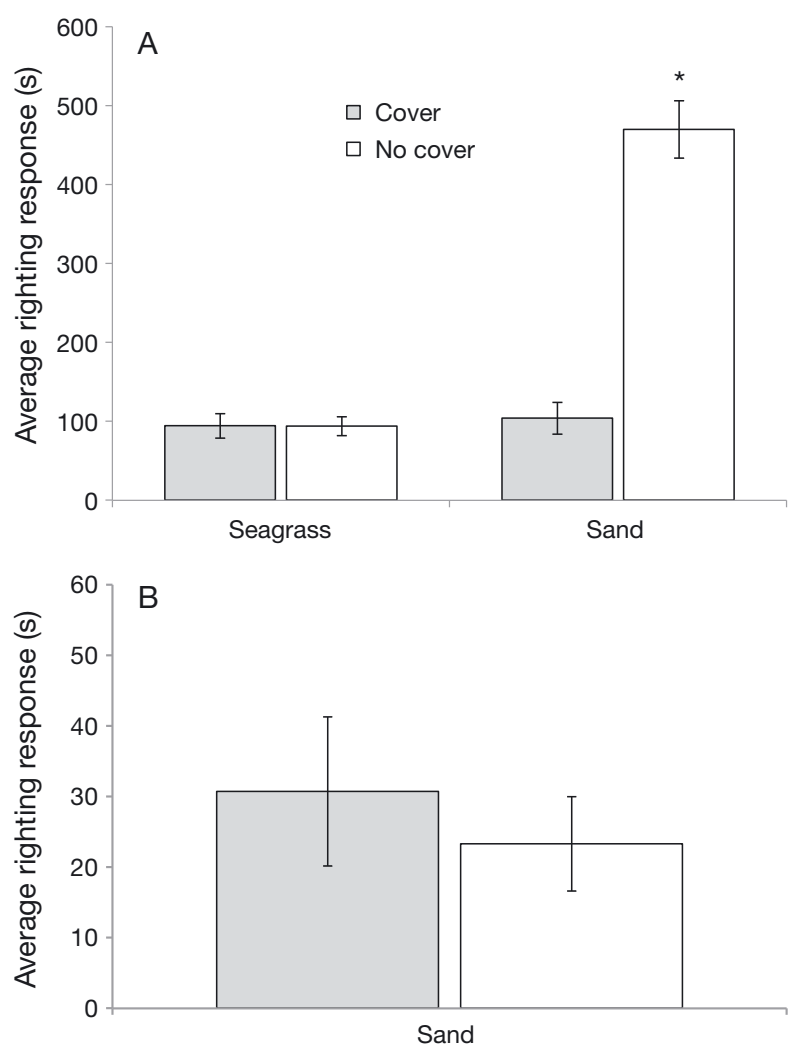

Fig. 3. Experiments in 2014 and 2015 in large sea urchins Lytechinus variegatus comparing substrate type and presence/absence of covering material ('cover'). (A) Mean $\pm \mathrm{SE}$ righting time for large sea urchins with/without cover in seagrass beds ( $\mathrm{n}=30$ in each treatment) or sand patches $(\mathrm{n}=20$ in each treatment) in 2014. ${ }^{*}$ Significantly different by 2 -way ANOVA as there was a significant interaction $(p<0.001)$ between substrate and presence/absence of cover. (B) Mean \pm SE righting time for large sea urchins on sand with/without cover in 2015 ( $\mathrm{n}=15$ for all treatments). Righting times were not significantly different by 1 -way ANOVA

within a seagrass patch were 5 times shorter than for sea urchins lacking covering material on a sand patch $(93.88 \pm 11.94$ vs. $469.85 \pm 36.34 \mathrm{~s})$.

\section{Water current measurements and righting}

In our 2015 experiment, righting response times on the 2 days were not significantly different (MannWhitney, $\mathrm{p}=0.119$ ); however, water velocities on the 2 days were significantly different (Mann-Whiney, $\mathrm{p}<0.001$ ) and therefore we were unable to combine the data as different substrates were tested on different days. On the first day, when experiments were performed in seagrass patches (with both presence and absence of covering material), there was little wind and our measured flow velocities averaged $0 \mathrm{~m}$ $\mathrm{s}^{-1}$ at the seafloor adjacent to sea urchins. On the sec- ond day, sea surface winds were notably stronger and flow velocities measured averaged $0.6 \mathrm{~m} \mathrm{~s}^{-1}$ adjacent to sea urchins. On this day, the righting times of sea urchins were tested on sand substrate and, in contrast to our 2014 experiment, the presence/ absence of covering material did not significantly affect righting times (Fig. 3B, 1-way ANOVA, p = 0.638). The majority of individuals $(80 \%)$ were observed to be assisted in righting by the strong wave action, with wave-generated currents physically flipping over sea urchins, rather than the sea urchins righting themselves. This passive wave-generated righting happened regardless of the presence/absence of sea urchin covering material. Although flow velocities were not measured during the experiments we conducted in 2014, these experiments were carried out at slack tide with no visible wave action and little wind, indicating low flow conditions.

\section{DISCUSSION}

The objective of the present study was to conduct in situ field observations of righting behavior in Lytechinus variegatus, including evaluations of the prospective impacts of body size (large versus small test diameter), covering material (presence versus absence of covering material), and substrate type (seagrass bed versus sand patch), in order to compare previous laboratory righting response times with righting times under natural conditions.

The present study indicates that the presence or absence of covering material (shell pieces, seagrass blades) in seagrass beds did not affect righting response times in any of the size classes of the sea urchin L. variegatus. Therefore, the physical disturbance of removing the covering material did not affect the urchins' ability to right, nor did the covering material itself obstruct it. However, when comparing between sea urchin size classes, smaller individuals (mean $1.67 \mathrm{~cm}$ diameter) righted 3 times faster than larger urchins (mean $4.07 \mathrm{~cm}$ diameter), regardless of the presence or absence of covering materials, when placed on seagrass substrates.

In terms of the impact of body size, our results are similar to righting measurements in laboratory studies carried out with other echinoids (Percy 1973, Sonnenholzner et al. 2010). For example, Percy (1973) noted in preliminary studies that righting time increased (lower activity coefficients) with increasing size (weight) in the sea urchin Strongylocentrotus droebachiensis, and Sonnenholzner et al. (2010) observed that large individuals of the sea urchin $S$. purpuratus 
had significantly longer righting times (lower activity coefficients) than those measured in small individuals. The reason(s) for size-based differences in the time required to right may reflect a simple physical relationship between the changes in surface area to volume ratio as individuals increase in size. Small individuals of a given species are generally able to generate greater forces relative to their body mass (Weihs 1977, Schmidt-Nielsen \& Duke 1984). This is because the cross-sectional area of muscle is squared while body mass is cubed as an individual increases in size. Thus, the larger an individual, the more mass per cross-sectional area of muscle the individual has to move. The ratio of spine length:urchin diameter may also change as sea urchins grow. In the present study, spine length:urchin diameter was significantly negatively correlated with size (Spearman's rank correlation, $\mathrm{p}<0.0001, \mathrm{n}=288$, data not shown), indicating that larger urchins have smaller spines and therefore sea urchins with longer spines may be more efficient at righting. It is also relevant that larger individuals exhibited significantly more variation in the time required to right than did small individuals. These observations highlight the importance of using consistent body sizes when measuring righting time as an indicator of stress to a given environmental factor. Moreover, small individuals offer the advantage of significantly reducing time spent carrying out righting measurements, as well as an inherent reduction in the variability of measurements.

In the present study, times required to right on sand were significantly reduced when covering material was present as opposed to when covering material was absent in 2014, yet not significantly different in 2015. Righting times of sea urchins on sand without covering material in 2014 averaged $469.9 \pm 36.3 \mathrm{~s}$ versus $23.3 \pm 6.7 \mathrm{~s}$ in 2015 . Although no water velocities were measured in 2014, water velocities measured in 2015 (average of $0.6 \pm 0.2 \mathrm{~m} \mathrm{~s}^{-1}$ ) were qualitatively noted as being of higher flow relative to the water currents observed in 2014. In 2015, urchins on sand were observed to right more quickly in situ with 'wave assists' regardless of whether covering material was present or not. In a separate, preliminary experiment simulating no flow conditions, where sea urchins without covering material were placed individually on sand in an aquarium along the shoreline (average diameter $4.4 \pm 0.2 \mathrm{~cm}, \mathrm{n}=10$ ), mean righting time was $562.5 \pm 25.7 \mathrm{~s}$ (data not shown). Therefore, covering material appears to play a significant role in facilitating the righting process under low flow, while at high flows the force of wind-generated currents facilitates rapid righting in $L$. variegatus.
Echinoid covering behavior is considered to be a reflexive response (Lawrence 1976a, Pawson \& Pawson 2013 and references within), yet there are likely both abiotic and biotic factors involved (Verling et al. 2004, Dumont et al. 2007, Chen \& Soong 2010, Pawson \& Pawson 2013). Previous in situ studies on several species of shallow-water sea urchins have reported that the extent of covering material is positively associated with higher degrees of wave action, suggesting that sea urchins are capable of detecting high flow and adding additional covering materials to serve as ballast to prevent dislodgement of the individual from the substratum (James 2000, Dumont et al. 2007). Both tube feet and spines are involved in the righting response in L. variegatus (Lawrence 1976b). When spines are clipped off at the base, spineless L. variegatus are still able to right themselves, yet righting response times (expressed as activity coefficients: 1000 / righting time in s, Percy 1973) are significantly reduced (Lawrence 1976b). The tube feet of many regular echinoids end in flat, terminal discs that are adhesive in nature and specialized for locomotion or maintaining position (Santos et al. 2009). The degree to which the spines versus the tube feet contribute to righting behavior is unknown, but the number and strength of the tube feet, as well as the length of the spines, are likely to have an important impact on righting time (Lawrence 1976b). L. variegatus has greater clinging power (adherence to an experimental substrate) on a smooth surface versus a rough surface (Sharp \& Gray 1962). Therefore, we hypothesize that covering materials held on the aboral test are released and then provide a solid surface for spines to push against and tube feet to attach to the surface and contract, thus assisting in righting. In the present study, individuals lacking covering material in sand patches were often incapable of righting within a $10 \mathrm{~min}$ period, suggesting that fine-grained sediments may not provide enough of a stable surface for righting forces (e.g. pushing or pulling against). These forces can be more effectively applied against a larger surface such as a rock or shell, or a surface that is attached to the sediment such as blades of the seagrass Thalassia testudinum. Indeed, in a separate preliminary experiment where we placed urchins in an aquarium in order to remove water velocity as a variable, we observed urchins making repeated righting attempts where an individual would achieve a 30 to $45^{\circ}$ angle relative to the sand surface and then collapse back onto their aboral test surface, apparently unable to maintain contact with the sand grains long enough to exert sufficient 'push' or 'pull' to 
achieve the $90^{\circ}$ angle necessary to right. Overall, we found that, with the notable exception of righting experiments carried out with a sand substrate and lack of available covering materials, mean righting times for $L$. variegatus in all experimental and control treatments were $\leq 2 \mathrm{~min}$ (or an activity coefficient $\geq 15$ ). These field-based righting times measured in the present study are similar to righting times for $L$. variegatus observed in control treatments under laboratory conditions (Kleitman 1941, Lawrence 1975, Böttger et al. 2001) and therefore validate the ecological relevance of laboratory righting measurements.

The greatly reduced capacity to right on soft bottom habitats has significant implications for $L$. variegatus, particularly as this relates to increased risk of predation. L. variegatus is predominantly found in locations characterized by little wave activity (Sharp \& Gray 1962, Watts et al. 2013) and has been observed to aggregate on sand flats of Saint Joseph's Bay, FL in winter months when the blades of $T$. testudinum are absent or significantly reduced in length (Beddingfield \& McClintock 2000). Populations have also been observed living on sand substrates in deeper offshore waters along the Florida gulf-coast shelf (Hill \& Lawrence 2003). Therefore, the results of the present study indicate that populations of $L$. variegatus may be more vulnerable to predation when displaced onto their aboral side in sandy areas that contain little covering material.

Acknowledgements. We thank C. Brothers and J. Schram for their assistance in the field and R. A. Angus and C. A. Katholi for their assistance with the statistical analysis.

\section{LITERATURE CITED}

Amato KR, Emel SL, Lindgren CA, Sullan KM, Wright PR, Gilbert JJ (2008) Covering behavior of two co-occurring Jamaican sea urchins: differences in the amount of covering and selection of covering material. Bull Mar Sci 82:255-261

Beddingfield SD, McClintock JB (2000) Demographic characteristics of Lytechinus variegatus (Echinoidea: Echinodermata) from three habitats in a north Florida bay, Gulf of Mexico. Mar Ecol 21:17-40

Binyon J (1972) Physiology of echinoderms. Pergamon Press, Oxford

Böttger SA, McClintock JB, Klinger TS (2001) Effects of inorganic and organic phosphates on feeding, feeding absorption, nutrient allocation, growth and righting responses of the sea urchin Lytechinus variegatus. Mar Biol 138:741-751

Challener RC, McClintock JB (2013) Exposure to extreme hypercapnia under laboratory conditions does not impact righting and covering behavior of juveniles of the common sea urchin Lytechinus variegatus. Mar Freshw
Behav Physiol 46:191-199

Chen A, Soong K (2010) 'Uncovering' behavior at spawning of the trumpet sea urchin Toxopneustes pileolus. Zool Stud 49:9

Conover WJ, Iman RL (1981) Rank transformations as a bridge between parametric and nonparametric statistics. Am Stat 35:124-129

* Dumont CP, Drolet D, Deschênes I, Himmelman JH (2007) Multiple factors explain the covering behavior in the green sea urchins, Strongylocentrotus droebachiensis. Anim Behav 73:979-986

Field GW (1892) The echinoderms of Kingston Harbor. Johns Hopkins University Circular 11:83

Giese AC, Farmanfarmaian A (1963) Resistance of the purple sea urchin to osmotic stress. Biol Bull 124:182-192

*Hill SK, Lawrence JM (2003) Habitats and characteristics of the sea urchins Lytechinus variegatus and Arbacia punctulata (Echinodermata) on the Florida gulf-coast shelf. Mar Ecol 24:15-30

Hyman LH (1955) The invertebrates. Vol IV: Echinodermata. McGraw-Hill, New York, NY

James DW (2000) Diet, movement, and covering behavior of the sea urchin Toxopneustes roseus in rhodolith beds in the Gulf of California, México. Mar Biol 137:913-923

Kleitman N (1941) The effect of temperature on the righting of echinoderms. Biol Bull 80:292-298

* Lares MT, McClintock JB (1991) The effects of temperature on the survival, organismal activity, nutrition, growth, and reproduction of the carnivorous, tropical sea urchin Eucidaris tribuloides. Mar Behav Physiol 19:75-96

Lawrence JM (1975) The effect of temperature-salinity combinations on the functional well-being of adult Lytechinus variegatus (Lamarck) (Echinodermata, Echinoidea). J Exp Mar Biol Ecol 18:271-275

* Lawrence JM (1976a) Covering response in sea urchins. Nature 262:490-491

Lawrence JM (1976b) On the role of the tube feet and spines in the righting response of sea urchins (Echinodermata: Echinoidea). Am Zool 16:228

*Pawson DL, Pawson DJ (2013) Bathyal sea urchins of the Bahamas, with notes on covering behavior in deep sea echinoids (Echinodermata: Echinoidea). Deep-Sea Res II 92:207-213

Percy JA (1973) Thermal adaptation in the boreo-arctic echinoid Strongylocentrotus droebachiensis (O. F. Müller, 1776). II. Seasonal acclimatization and urchin activity. Physiol Zool 46:129-138

Reese ES (1966) The complex behavior of echinoderms. In: Boolootian RA (ed) Physiology of Echinodermata. Interscience Publishers, New York, NY, p 157-218

Santos R, Hennebert E, Coelho AV, Flammang P (2009) The echinoderm tube foot and its role in temporary underwater adhesion. In: Stanislav NG (ed) Functional surfaces in biology: adhesion related phenomena. Springer, Dordrecht, p 9-41

Schapiro SJ, Everitt JI (2006) Preparation of animals for use in the laboratory: issues and challenges for the institutional animal care and use committee (IACUC). ILAR J 47:370-375

* Scheibling RE, Stephenson RL (1984) Mass mortality of Strongylocentrotus droebachiensis (Echinodermata: Echinoidea) off Nova Scotia, Canada. Mar Biol 78:153-164

Schmidt-Nielsen K, Duke JB (1984) Scaling: Why is animal size so important? Cambridge University Press, Cambridge Schneider CA, Rasband WS, Eliceiri KW (2012) NIH Image 
to ImageJ: 25 years of image analysis. Nat Methods 9: 671-675

Sharp DT, Gray IE (1962) Studies on factors affecting the local distribution of two sea urchins, Arbacia punctulata and Lytechinus variegatus. Ecology 43:309-313

Sonnenholzner JI, Montaño-Moctezuma G, Searcy-Bernal R (2010) Effect of three tagging methods on the growth and survival of the purple sea urchins Strongylocentrotus purpuratus. Pan-Am J Aquat Sci 5:414-420

Verling E, Crook AC, Barnes DKA (2004) The dynamics of

Editorial responsibility: Anna Metaxas,

Halifax, Nova Scotia, Canada covering behaviour in dominant echinoid populations from American and European west coasts. Mar Ecol 25: 191-206

Watts SA, McClintock JB, Lawrence JM (2013) Lytechinus. In: Lawrence JM (ed) Sea urchins: biology and ecology, 3rd edn. Elsevier, Amsterdam, p 475-490

Weihs D (1977) Effects of size on sustained swimming speeds of aquatic organisms. In: Pedley TJ (ed) Scale effects in animal locomotion. Academic Press, New York, NY, p 333-339

Submitted: August 15, 2016; Accepted: December 12, 2016 Proofs received from author(s): February 10, 2017 